\title{
Correction to: Public Health Approaches to Type 2 Diabetes Prevention: the US National Diabetes Prevention Program and Beyond
}

\author{
Stephanie M. Gruss ${ }^{1} \cdot$ Kunthea Nhim $^{1} \cdot$ Edward Gregg $^{2} \cdot$ Miriam Bell $^{1} \cdot$ Elizabeth Luman $^{1} \cdot$ Ann Albright $^{1}$ \\ Published online: 27 June 2020 \\ (C) Springer Science+Business Media, LLC, part of Springer Nature 2020
}

\section{Correction to: Current Diabetes Reports (2019) 19: 78} https://doi.org/10.1007/s11892-019-1200-z

The original version of this review article unfortunately contained a mistake in the first paragraph of "Measures and Methods" section. Reference citation "[40]" should be changed to "[37]".

The sentence should read: "Average weight loss and physical activity minutes per week were calculated among participants who attended $\geq 3$ sessions in the first 6 months and whose time from first session attended to last session attended was $\geq$ 9 months. CDC considers this threshold to be the minimum dose to begin seeing lifestyle and weight change that can impact type 2 diabetes [37].”

Publisher's Note Springer Nature remains neutral with regard to jurisdictional claims in published maps and institutional affiliations.

The online version of the original article can be found at https://doi.org/ $10.1007 /$ s11892-019-1200-z

Stephanie M. Gruss

inf6@cdc.gov

Kunthea Nhim

knhim@cdc.gov

Edward Gregg

e.gregg@imperial.ac.uk

Miriam Bell

omw5@cdc.gov
Elizabeth Luman

ec17@cdc.gov

Ann Albright

aga6@cdc.gov

Division of Diabetes Translation, Centers for Disease Control and Prevention, 4770 Buford Hwy., Mailstop F75, Atlanta, GA 30341, USA

2 Department of Epidemiology and Biostatistics, School of Public Health, Imperial College London, London, UK 